\title{
Hepatocyte cholesterol content modulates glucagon receptor signalling
}

Emma Rose McGlone ${ }^{1,2}$, T. Bertie Ansell ${ }^{3}$, Cecilia Dunsterville ${ }^{2}$, Wanling Song ${ }^{3,5}$, David Carling ${ }^{4}$, Alejandra Tomas², Stephen R Bloom², Mark S. P. Sansom ${ }^{3,}$, Tricia Tan², Ben Jones $^{2, *}$.

${ }^{1}$ Department of Surgery and Cancer, Imperial College London, London W12 0NN, United Kingdom.

${ }^{2}$ Department of Metabolism, Digestion and Reproduction, Imperial College London, London W12 0NN, United Kingdom.

${ }^{3}$ Department of Biochemistry, University of Oxford, Oxford OX1 3QU, United Kingdom.

${ }^{4}$ Cellular Stress Research Group, MRC London Institute of Medical Sciences, Imperial College London, London W12 0NN, United Kingdom.

${ }^{5}$ Current address: Rahko, Clifton House, 46 Clifton Terrace, Finsbury Park, London N4 3JP, United Kingdom.

*Correspondence to: ben.jones@imperial.ac.uk or mark.sansom@bioch.ox.ac.uk 


\section{Summary}

Glucagon decreases liver fat, and non-alcoholic fatty liver disease (NAFLD) is associated with hepatic glucagon resistance. Increasingly it is recognised that the function of G proteincoupled receptors can be regulated by their local plasma membrane lipid environment. The aim of this study was to evaluate the effects of experimentally modulating hepatocyte cholesterol content on the function of the glucagon receptor (GCGR). We found that glucagon-mediated cAMP production is inversely proportional to cholesterol content of human hepatoma and primary mouse hepatocytes after treatment with cholesteroldepleting and loading agents, with ligand internalisation showing the opposite trend. Mice fed a high cholesterol diet had increased hepatic cholesterol and a blunted hyperglycaemic response to glucagon, both of which were partially reversed by simvastatin. Molecular dynamics simulations identified potential membrane-exposed cholesterol binding sites on the GCGR. Overall, our data suggest that increased hepatocyte membrane cholesterol could directly contribute to glucagon resistance in NAFLD.

\section{Keywords}

Glucagon, glucagon receptor, cholesterol, cell membrane, non-alcoholic fatty liver disease, type 2 diabetes mellitus 


\section{Introduction}

Glucagon is a key hormone in the control of hepatic metabolism: as well as increasing glucose production to counteract hypoglycaemia, it reduces liver fat by decreasing de novo lipogenesis and increasing fatty acid oxidation (Longuet et al., 2008; Penhos et al., 1966). Patients with type 2 diabetes mellitus (T2DM) and/or non-alcoholic fatty liver disease (NAFLD) exhibit hepatic glucagon resistance (Demant et al., 2018; Suppli et al., 2020), which in turn contributes to worsening of steatosis by blocking the beneficial effects of glucagon on hepatic lipid metabolism. To date, the mechanism behind this phenomenon is incompletely understood (Janah et al., 2019). Hepatic cholesterol accumulation is a feature of NAFLD and, interestingly, the degree of both glucagon resistance (Gar et al., 2021) and hepatic cholesterol accumulation (Min et al., 2012; Puri et al., 2007) are correlated with histological severity of the disease.

The glucagon receptor (GCGR) is a prototypical class B G protein-coupled receptor (GPCR). It is increasingly appreciated that the functions of cell surface GPCRs are heavily modulated by other membrane components (Thal et al., 2018) including lipids (Reiter et al., 2017). This can occur either through direct lipid-receptor interactions (Duncan et al., 2020b), or indirectly, e.g. by altering the properties of the membrane bilayer (Mahmood et al., 2013). Cholesterol is known to alter the conformation of some GPCRs by directly binding to allosteric sites (Casiraghi et al., 2016; Manna et al., 2016); it is also a key structural component of the plasma membrane that controls the distribution and spatial coupling between surface receptors and intracellular mediators (Simons and Ikonen, 2000). We have recently demonstrated that cholesterol depletion affects signalling and endomembrane trafficking of the closely related 
glucagon-like peptide 1 receptor (GLP-1R) (Buenaventura et al., 2019). To date, the relevance of cellular cholesterol to GCGR signalling has not been explored experimentally.

The aim of this study was to investigate whether hepatocyte cholesterol content affects GCGR signalling and its downstream physiological correlates. Here we demonstrate that enrichment of cholesterol in vitro and in vivo decreases glucagon responsiveness. Cholesterol depletion has the opposite effect. Molecular dynamics simulations identify likely cholesterol binding sites on the GCGR which may allosterically regulate its function. Our results indicate that hepatocyte cholesterol content contributes to hepatic glucagon sensitivity and pinpoint a likely molecular basis for this phenomenon. Increased cellular cholesterol, by directly interacting with the hepatic GCGR, could contribute to glucagon resistance in patients with NAFLD. 


\section{Results}

\section{Manipulating cellular cholesterol content has divergent effects on GCGR-mediated}

\section{signalling and ligand uptake}

We first examined the impact of pharmacological modulation of cellular cholesterol levels on GCGR function. As hepatoma cells lack the high levels of GCGR expression typical of primary hepatocytes, we used Huh7 cells with exogenous GCGR expression for these studies (McGlone et al., 2021). cAMP signalling responses to glucagon stimulation in Huh7-GCGR cells treated with different concentrations of cholesterol-free methyl- $\beta$-cyclodextrin (M $\beta C D)$, which rapidly extracts cholesterol from cellular membranes, showed an increase in potency and, at the highest $M \beta C D$ concentration $(10 \mathrm{mM})$, a trend $(p=0.06)$ towards increased maximum response (Figure 1A; Table 1). Conversely, incubating with cholesterol-saturated $M \beta C D$ to increase membrane cholesterol levels caused a reduction in cAMP signalling (Figure 1A; Table 1). Pre-treatment of Huh7-GCGR cells with simvastatin to inhibit cellular cholesterol synthesis also increased potency for cAMP in response to glucagon (Figure 1B; Table 1). This effect was reversed by concurrent pre-treatment with mevalonate to replenish the product of the statin-inhibited 3-hydroxy-3-methyl-glutaryl-coenzyme A (HMG-CoA) reductase reaction, and by acute restoration of membrane cholesterol levels using cholesterolsaturated $M \beta C D$. When we compared the relative cellular cholesterol content obtained in these assays against corresponding cAMP responses, a robust inverse correlation was seen $\left(R^{2}=0.78, p=0.0003 ;\right.$ Figure $\left.1 C\right)$.

GCGR shows a biphasic CAMP concentration-relationship due to superimposed effects of $\mathrm{G}_{\mathrm{s}^{-}}$ mediated stimulation and $\mathrm{G \alpha}_{\mathrm{i}}$-mediated inhibition of cAMP production (Grady et al., 1987). 
We investigated the effects of modifying cellular cholesterol content on the $G \alpha_{s}$ and $G \alpha_{i}$ components of the overall cAMP response by performing experiments with and without the $G \alpha_{i}$ inhibitor pertussis toxin (PTX) (Yajima et al., 1978) (Figure 1D, 1E, Table 1). The $G \alpha_{i}$ response required at least 10 -fold higher glucagon concentrations than the $\mathrm{G} \alpha_{s}$ response, and the balance between each component was not significantly affected by acute cholesterol depletion or loading, or by sustained cholesterol reduction with simvastatin (Figure 1F).

GCGR ligand internalisation represents an additional downstream functional readout of GCGR activation. We examined this phenomenon in Huh7-GCGR cells following treatment with cholesterol lowering or enriching agents using fluorescein isothiocyanate-tagged glucagon ("FITC-GCG"), which closely mimics the pharmacology of native glucagon (McGlone et al., 2021). In contrast to the effects on cAMP signalling, we found an increase in FITC-GCG uptake after cholesterol loading, and a decrease after cholesterol depletion (Figure 1G, 1H, Table 1). In experiments designed to determine the effect of simvastatin pre-treatment, FITC-GCG uptake showed lower potency for all conditions, precluding accurate assessment of the effects of each treatment on FITC-GCG uptake $\mathrm{EC}_{50}$ (Figure 1I, 1J). This may have been a result of the prolonged serum starvation period typically used in simvastatin incubations, which itself leads to loss of membrane cholesterol due to the absence of serum lipoproteins. Across all assays, a positive correlation was observed between FITC-GCG uptake and cellular cholesterol content $\left(R^{2}=0.55, p=0.01 ;\right.$ Figure $\left.1 K\right)$. 
A
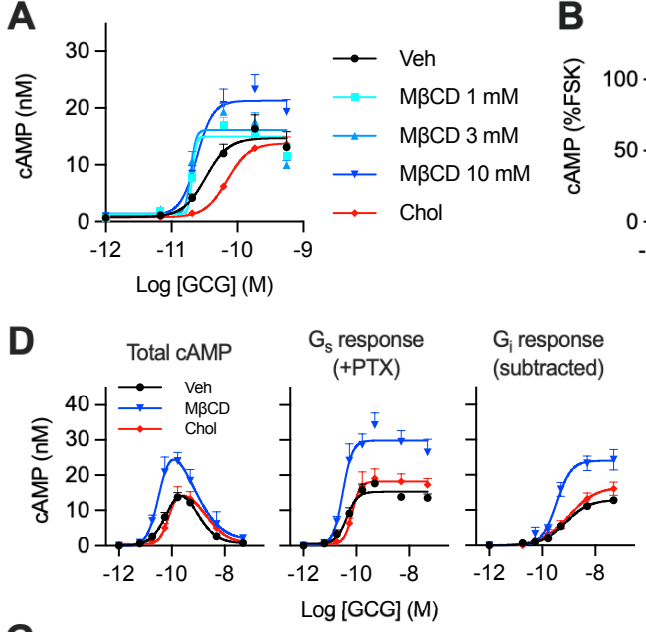

G

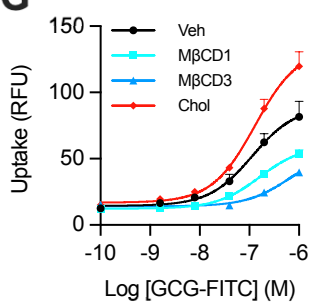

|

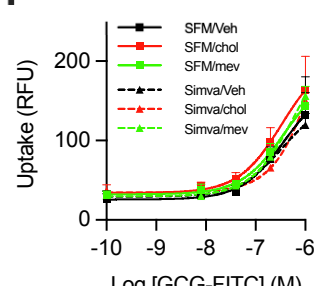

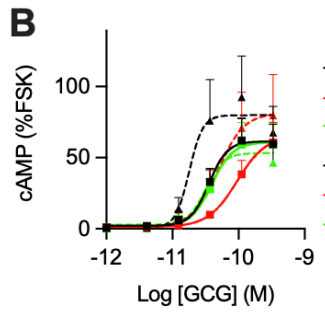

E Total cAMP

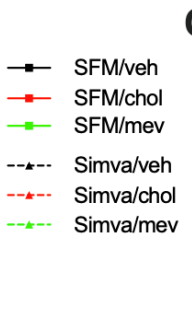

$\log [\mathrm{GCG}](\mathrm{M})$

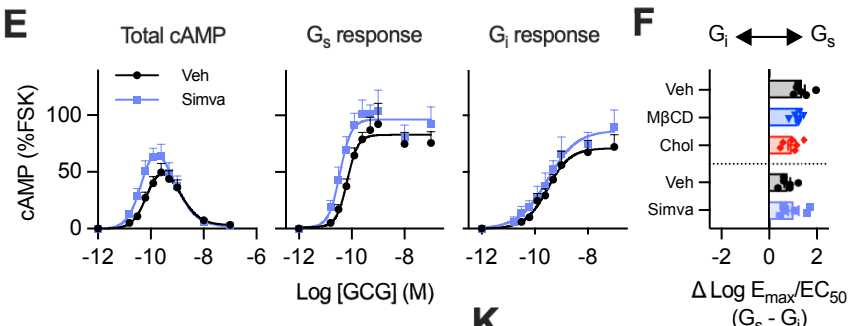

C

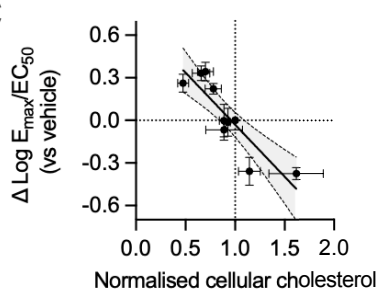

$F$ $\left(G_{s}-G_{i}\right)$
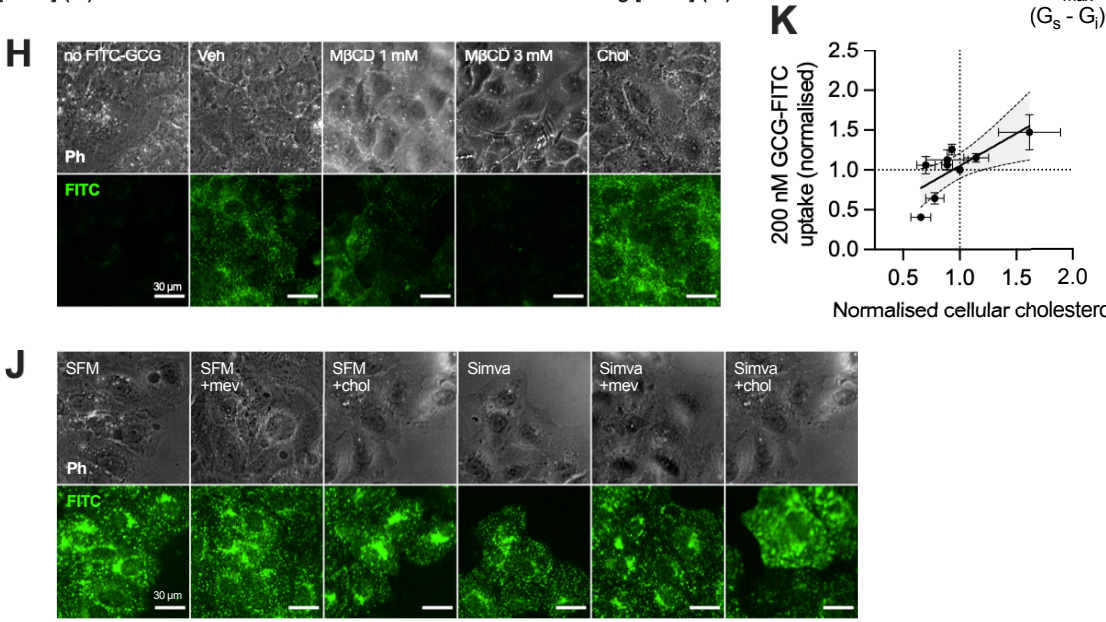

Figure 1: Increasing cellular cholesterol decreases agonist-stimulated cAMP production at GCGR whilst increasing agonist uptake in vitro. (A) CAMP concentration response curves in Huh7-GCGR cells pre-treated with cholesterol-deplete $\mathrm{M} \beta C D$ or cholesterol-saturated $\mathrm{M} \beta C D$ (Chol; $50 \mu \mathrm{g} / \mathrm{ml}$ ), then stimulated with glucagon (GCG) $n=4$; or (B) pre-treated with simvastatin (Simva) or serum-free medium (SFM) overnight, with concurrent or subsequent treatment with or without mevalonate (mev; $50 \mu \mathrm{M}$ ) or cholesterol-saturated $\mathrm{M} \beta C D$, then stimulated with glucagon. Results in (B) were normalised to forskolin responses (FSK; $10 \mu M$ ), $n=5$. (C) Association between a combined measure of cAMP efficacy and potency (log-transformed $\mathrm{E}_{\max } / \mathrm{EC}_{50}$ ) and cellular cholesterol for each of the treatments shown in (A) and (B), both normalised to vehicle control, with linear regression line $\pm 95 \%$ confidence intervals shown. (D) cAMP responses over a wider glucagon concentration range with or without pertussis toxin pre-treatment (PTX; $10 \mathrm{ng} / \mathrm{ml}$ ) to block $\mathrm{G} \alpha_{\mathrm{i}}$-mediated cAMP inhibition and reveal the $G \alpha_{s}$-specific response, $n=6$. The effect of pre-treatment with $M \beta C D$ or cholesterol is shown. (E) As for (D) but the effect of overnight pre-treatment with simvastatin, $n=6$. (F) Balance between $\mathrm{Ga}_{\mathrm{s}}$ and $\mathrm{Ga}_{\mathrm{i}}$-mediated cAMP effects from (D) and (E); all inter-group statistical comparisons non-significant. (G) The effect of pretreatment with $M \beta C D$ or cholesterol on FITC-GCG uptake in Huh7-GCGR cells, $n=5$; with representative phase contrast (Ph) and FITC-epifluorescence images shown in (H). Scale bar $=30 \mu \mathrm{m}$. (I) and (J) are similar to (G) and $(\mathrm{H})$ but showing the effect of simvastatin \pm mevalonate \pm cholesterol, $n=4$, scale bar $=30 \mu \mathrm{m}$. (K) Association between FITC-GCG uptake at $200 \mathrm{nM}$ and cellular cholesterol content for each of the treatments shown in (G) and $(\mathrm{I})$, with linear regression line $\pm 95 \%$ confidence intervals shown. Data are shown as mean + or \pm SEM. 


\begin{tabular}{|c|c|c|c|c|c|c|c|c|c|}
\hline \multicolumn{10}{|c|}{ Acute treatments } \\
\hline & & Vehicle & \multicolumn{2}{|c|}{$\mathrm{M} \beta C D(1 \mathrm{mM})$} & \multicolumn{2}{|c|}{$\mathrm{M} \beta C D(3 \mathrm{mM})$} & \multicolumn{2}{|c|}{$\begin{array}{l}\mathrm{M} \beta C D(10 \\
\mathrm{mM})\end{array}$} & Cholesterol \\
\hline \multirow[t]{2}{*}{$\begin{array}{l}\text { cAMP } \\
\text { (Fig 1A) }\end{array}$} & $\begin{array}{l}\log \mathrm{EC}_{50} \\
(\mathrm{M})\end{array}$ & $-10.5 \pm 0.0$ & \multicolumn{2}{|l|}{$-10.7 \pm 0.0 *$} & \multicolumn{2}{|c|}{$-10.8 \pm 0.1 *$} & \multicolumn{2}{|c|}{$-10.6 \pm 0.1$} & $-10.2 \pm 0.0 *$ \\
\hline & $\begin{array}{l}E_{\max }(n M \\
c A M P)\end{array}$ & $14.9 \pm 2.7$ & \multicolumn{2}{|l|}{$15.0 \pm 1.2$} & \multicolumn{2}{|c|}{$16.1 \pm 0.5$} & \multicolumn{2}{|c|}{$21.9 \pm 2.4$} & $14.8 \pm 1.6$ \\
\hline \multirow[t]{2}{*}{$\begin{array}{l}G \alpha_{s} \text { (Fig } \\
\text { 1D) }\end{array}$} & $\begin{array}{l}\log \mathrm{EC}_{50} \\
(\mathrm{M})\end{array}$ & $-10.4 \pm 0.1$ & \multicolumn{2}{|l|}{ n.d. } & \multicolumn{2}{|c|}{$-10.5 \pm 0.1$} & \multicolumn{2}{|c|}{ n.d. } & $-10.0 \pm 0.1 * *$ \\
\hline & $\begin{array}{l}E_{\max }(\mathrm{nM} \\
\text { cAMP) }\end{array}$ & $15.4 \pm 1.0$ & \multicolumn{2}{|l|}{ n.d. } & \multicolumn{2}{|c|}{$31.3 \pm 3.0 * * *$} & \multicolumn{2}{|c|}{ n.d. } & $19.6 \pm 2.0$ \\
\hline \multirow[t]{2}{*}{$\begin{array}{l}\mathrm{G} \alpha_{\mathrm{i}} \text { (Fig } \\
\text { 1D) }\end{array}$} & $\begin{array}{l}\log E_{50} \\
(\mathrm{M})\end{array}$ & $-9.1 \pm 0.1$ & \multicolumn{2}{|l|}{ n.d. } & \multicolumn{2}{|c|}{$-9.4 \pm 0.2$} & \multicolumn{2}{|l|}{ n.d. } & $-9.2 \pm 0.3$ \\
\hline & $\begin{array}{l}\mathrm{E}_{\max }(\mathrm{nM} \\
\mathrm{cAMP})\end{array}$ & $13.4 \pm 1.0$ & \multicolumn{2}{|l|}{ n.d. } & \multicolumn{2}{|c|}{$26.1 \pm 3.0 * * *$} & \multicolumn{2}{|c|}{ n.d. } & $16.6 \pm 2.0$ \\
\hline \multirow{3}{*}{$\begin{array}{l}\text { GCG- } \\
\text { FITC } \\
\text { uptake } \\
\text { (Fig 1G) }\end{array}$} & $\begin{array}{l}\log \mathrm{EC}_{50} \\
(\mathrm{M})\end{array}$ & $-6.9 \pm 0.2$ & $-6.8 \pm 0.1$ & & -6.2 & $2 * *$ & n.d. & & $-6.9 \pm 0.1$ \\
\hline & $\begin{array}{l}\mathrm{E}_{\max } \\
(\mathrm{RFU})\end{array}$ & $89.4 \pm 8.0$ & $60.1 \pm 3.0^{*}$ & & 56.5 & $4^{*}$ & n.d. & & $133.0 \pm 8.0^{* *}$ \\
\hline & $\begin{array}{l}200 \mathrm{nM} \\
(\mathrm{RFU})\end{array}$ & $62.5 \pm 6.3$ & $38.8 \pm 2.0^{*}$ & & 24.6 & $.8 * * *$ & n.d. & & $87.8 \pm 7.0 * *$ \\
\hline Overnigh & treatment & & & & & & & & \\
\hline & & SFM & SFM + Chol & $\begin{array}{l}\mathrm{SFI} \\
\mathrm{Me}\end{array}$ & & Simva & & $\begin{array}{l}\text { Simva + } \\
\text { Chol }\end{array}$ & $\begin{array}{l}\text { Simva + } \\
\text { Mev }\end{array}$ \\
\hline $\begin{array}{l}\text { cAMP } \\
\text { (Fig 1B) }\end{array}$ & $\begin{array}{l}\log \mathrm{EC}_{50} \\
(\mathrm{M})\end{array}$ & $-10.5 \pm 0.1$ & $-10.0 \pm 0.1 *$ & $\begin{array}{l}-10 \\
0.0\end{array}$ & $3 \pm$ & $\begin{array}{l}-10.7 \pm \\
*\end{array}$ & & $-10.3 \pm 0.1$ & $-10.5 \pm 0.0$ \\
\hline & $\begin{array}{l}E_{\max }(\% \\
F S K)\end{array}$ & $61.4 \pm 14.1$ & $69.0 \pm 18.6$ & $\begin{array}{l}62 \\
16 \\
\end{array}$ & & $83.8 \pm$ & 24.3 & $82.5 \pm 29.9$ & $50.9 \pm 14.9$ \\
\hline $\begin{array}{l}\mathrm{G} \alpha_{\mathrm{s}} \text { (Fig } \\
1 \mathrm{E})\end{array}$ & $\begin{array}{l}\log \mathrm{EC}_{50} \\
(\mathrm{M})\end{array}$ & $-10.2 \pm 0.1$ & n.d. & n.c & & $\begin{array}{l}-10.4 \pm \\
* * *\end{array}$ & & n.d. & n.d. \\
\hline & $\begin{array}{l}E_{\max }(\% \\
F S K)\end{array}$ & $84.0 \pm 11.5$ & n.d. & n.c & & $98.6 \pm$ & 2.4 & n.d. & n.d. \\
\hline $\begin{array}{l}\text { Go } \alpha_{i} \text { (Fig } \\
1 E)\end{array}$ & $\begin{array}{l}\log E_{50} \\
(\mathrm{M})\end{array}$ & $-9.5 \pm 0.1$ & n.d. & n.c & & $-9.5 \pm c$ & & n.d. & n.d. \\
\hline & $\begin{array}{l}E_{\max }(\% \\
F S K)\end{array}$ & $73.7 \pm 11.4$ & n.d. & n.c & & $90.9 \pm$ & 14.0 & n.d. & n.d. \\
\hline $\begin{array}{l}\text { GCG- } \\
\text { FITC } \\
\text { uptake } \\
\text { (Fig 1I) }\end{array}$ & $\begin{array}{l}200 \mathrm{nM} \\
(\mathrm{RFU})\end{array}$ & $78.5 \pm 13.4$ & $98.6 \pm 17.7$ & $\begin{array}{l}85 \\
10\end{array}$ & & $89.2 \pm$ & 2.8 & $85.1 \pm 19.2$ & $79.8 \pm 6.9$ \\
\hline
\end{tabular}

Table 1: cAMP responses to glucagon and FITC-GCG uptake in Huh7-GCGR cells following cellular cholesterol manipulation. Parameter estimates \pm SEM from responses depicted in Figure 1 . For uptake assays, $E_{\max }$ and $E C_{50}$ are derived from pooled data before statistical analysis. Mean $\pm \mathrm{SEM} ; n=4$ or 5 . Uptake at a single concentration of FITC-GCG $(200 \mathrm{nM})$ is presented because $E_{\max }$ and $\mathrm{EC}_{50}$ could not be derived from the curves for overnight treatments. Treatment effects were analysed using matched 1-way ANOVA and compared to vehicle with Dunnett's multiple comparison test, or by paired t-test where there are only 2 groups. "n.d." indicates not done. $*_{\mathrm{p}}<0.05 ; *^{*} \mathrm{p}<0.01 ; * * * \mathrm{p}<0.001$. 


\section{Molecular dynamics simulations reveal potential GCGR-cholesterol binding sites}

To explore the potential for direct interactions between the GCGR and cholesterol in the plasma membrane as an underlying mechanism for our pharmacological observations, we performed coarse-grained molecular dynamics (MD) simulations of GCGR interactions with bilayer lipids when in active and inactive states. A single receptor molecule was simulated whilst embedded in plasma membrane mimetic bilayers containing $25 \%$ cholesterol. The locations of predicted cholesterol binding sites with the four highest cholesterol residence times were the same for the two GCGR conformations (Figure 2A, 2B, Supplementary Video 1). These correspond to a binding site between helices TM1 and TM2 (site-1), the extracellular portion of TM3/TM4 (site-2), an intracellular site formed by TM5, ICL3 and TM6 (site-3), and a densely packed site at the centre of TM6/TM7 (site-4). We note that for site-1, in the inactive conformation interacting residues were diffuse (Figure $2 \mathrm{~A}$ ), whereas in the active GCGR conformation they were restricted to the extracellular region (Figure 2B). The residues involved in formation of other sites were in broad agreement. There were small differences in the relative residence time order of the top four sites between the two receptor conformations. For the active GCGR conformation, cholesterol binding sites in proximity to TM5/TM6 (site-3 and site-4) were stabilised and site-2 interactions were destabilised when compared to the inactive conformation. These findings indicate that, whilst the location of key cholesterol binding sites is relatively insensitive to GCGR conformation, receptor activation induces subtle changes in cholesterol interactions that result in more prolonged residence times around TM5, ICL3, TM6 and TM7. Simulations performed using membrane bilayers with varying cholesterol content (Ansell et al., 2021) allowed us to estimate apparent dissociation constants for cholesterol at each site (Figure $2 \mathrm{C}$ ): $\mathrm{K}_{d}$ app at site- $1: 10.7 \pm 0.3 \%$; site2: $18.3 \pm 0.4 \%$; site-3: $15.0 \pm 0.8 \%$; and site- $4: 6.6 \pm 0.1 \%$. 
Site-3 overlaps with the experimentally verified G protein binding site for GCGR and other class B GPCRs (Liang et al., 2017; Qiao et al., 2020). Moreover, site-4 corresponds to TM6, which tilts outwards during receptor activation to accommodate G protein binding. In view of the inverse correlation between membrane cholesterol content and cAMP signalling (Figure 1C), we hypothesised that cholesterol could act as a negative allosteric regulator at sites-3/4 (Abiko et al., 2021) by reducing the capacity of the receptor to interact with $\mathrm{G}_{\mathrm{s}}$. This possibility was supported by studies measuring recruitment to the receptor of mini- $G_{s}, a$ conformational biosensor for $\mathrm{G \alpha}_{\mathrm{s}}$-favouring active GPCR conformations (Nehme et al., 2017), in which cholesterol loading reduced glucagon-stimulated GCGR-mini-Gs interactions (Figure 2D).

A

GCGR (inactive)

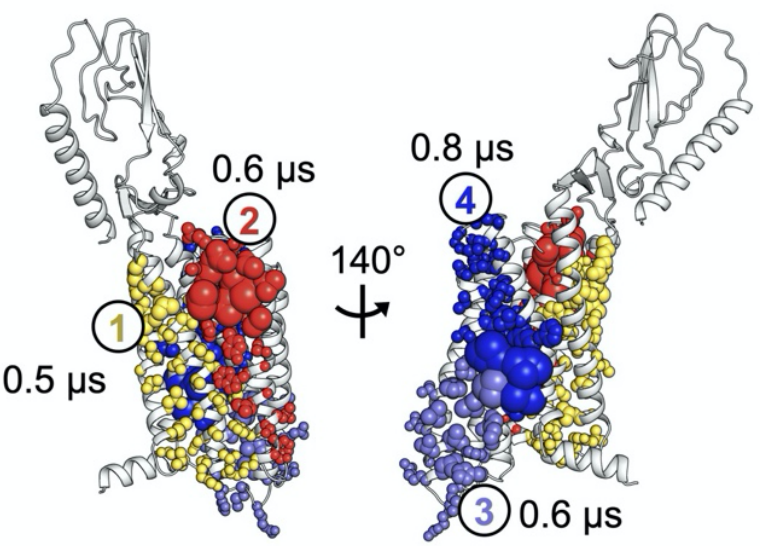

C

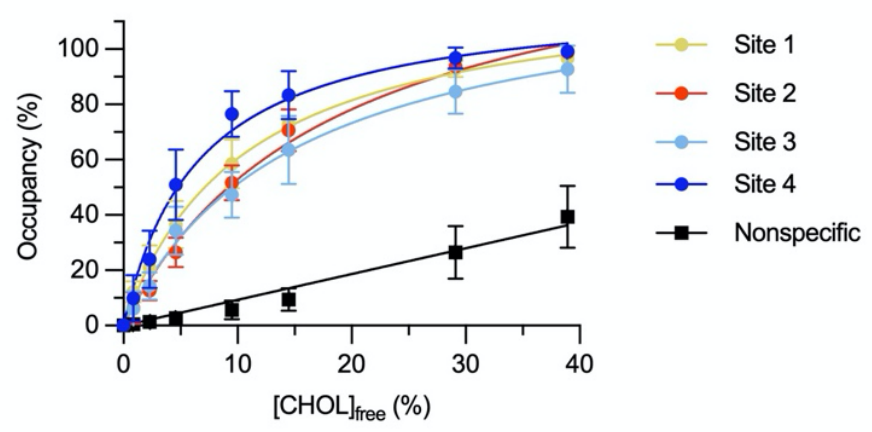

B

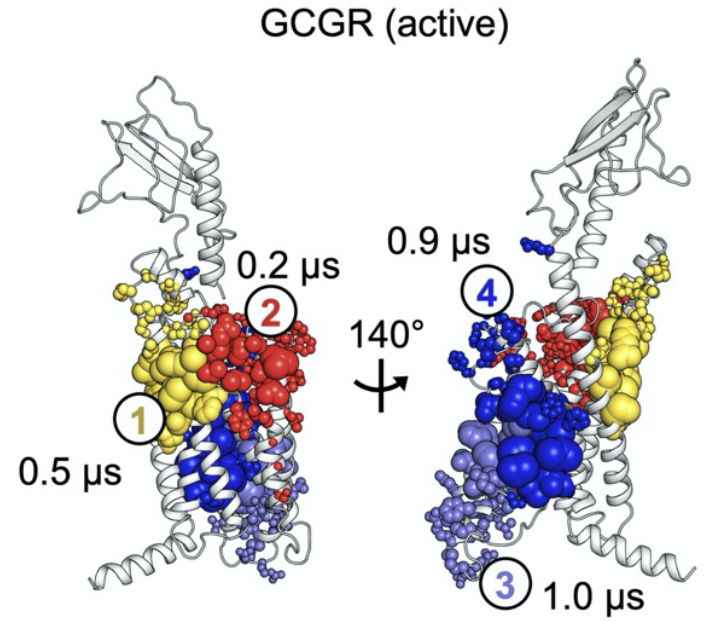

D

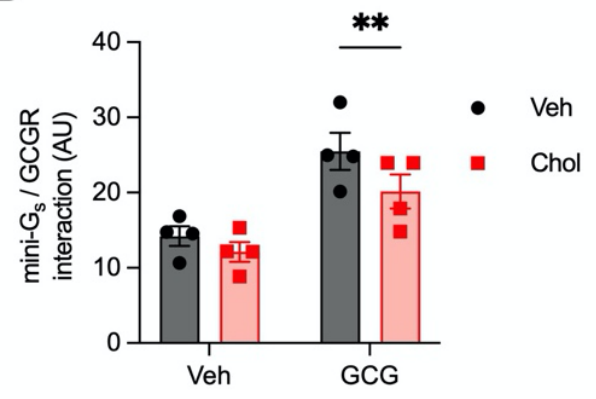


Figure 2: Predicted GCGR-cholesterol interactions. The top four ranked binding sites for cholesterol from coarse-grained MD simulations of the glucagon receptor (GCGR) in inactive (A) and active (B) conformations in plasma membrane-like bilayers containing $25 \%$ cholesterol. Each conformation was simulated for $10 \times 10 \mu \mathrm{s}$. Distinct binding sites are coloured yellow (site-1), red (site-2), lilac (site-3) and blue (site-4). Residues comprising each site are shown as spheres scaled by per residue cholesterol residence times. The residence time for cholesterol binding to each site is indicated. Binding sites and associated residence times were calculated using PyLipID (Song et al., 2021). (C) Binding saturation curves for cholesterol binding to each site from equilibrium MD simulations ( $5 \times 5 \mu$ s at each \% free cholesterol). Site \% occupancy was calculated using PyLipID and plotted against the free cholesterol \% (see methods) in binary bilayers composed of POPC and cholesterol. (D) Normalised AUC for luminescent signal indicating interaction between GCGR-SmBiT and mini-Gs-LgBiT in HEK293T cells treated with $100 \mathrm{nM}$ glucagon or vehicle for $30 \mathrm{~min}, n=4$, compared by 2-way repeated measures ANOVA with Sidak's test. ${ }^{* *} \mathrm{p}<0.01$. Data are shown as mean $\pm \mathrm{SEM}$, with individual experimental replicates in Fig 2D.

\section{Increasing hepatic cholesterol in mice decreases glucagon sensitivity}

Next we manipulated hepatic cholesterol in adult mice using isocaloric chow high or low in cholesterol, with or without simvastatin. While these diets had no effect on body weight or hepatic triglyceride content (Figures 3A, 3B), the cholesterol-enriched diet caused a dramatic increase in hepatic cholesterol after 1 week, which was partially abrogated by the inclusion of simvastatin (Figure 3C). Following an intra-peritoneal glucagon/pyruvate challenge test, we observed that the expected glucagon-induced peak in glycaemia was absent in mice that had been fed the high cholesterol diet, but partly restored in mice fed the combined cholesterol and simvastatin diet (Figure 3D). There was also an inverse association between hepatic cholesterol and the glucose excursion conferred by addition of glucagon $\left(R^{2}=0.14 ; p=0.02\right.$; Figure $3 \mathrm{E})$.

Ex vivo, loading of wild-type primary murine hepatocytes with $150 \mu \mathrm{g} / \mathrm{ml}$ cholesterol led to a significant reduction in cAMP potency for glucagon, while $50 \mu \mathrm{g} / \mathrm{ml}$ had a more modest effect (Figure 3F, 3G). Prior treatment of primary hepatocytes overnight with simvastatin increased glucose output in response to glucagon stimulation (Figure $3 \mathrm{H}$ ). 

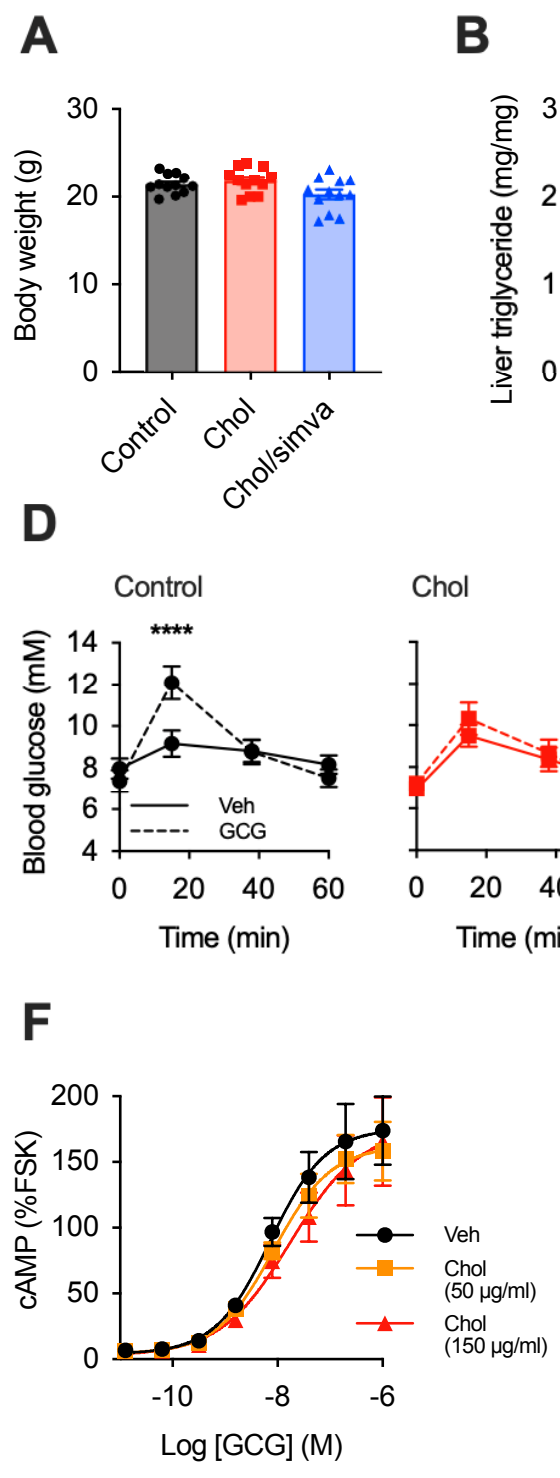

B

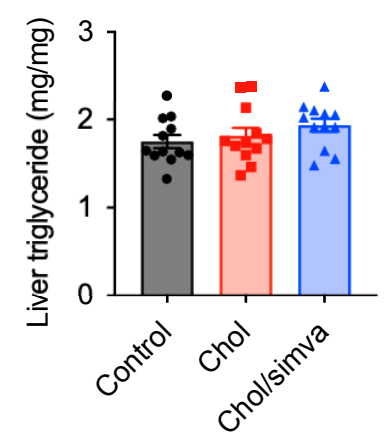

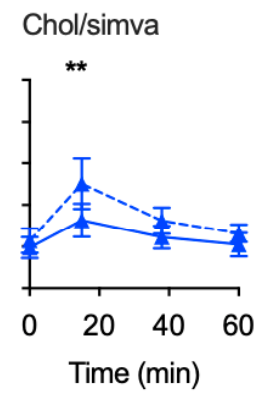

G

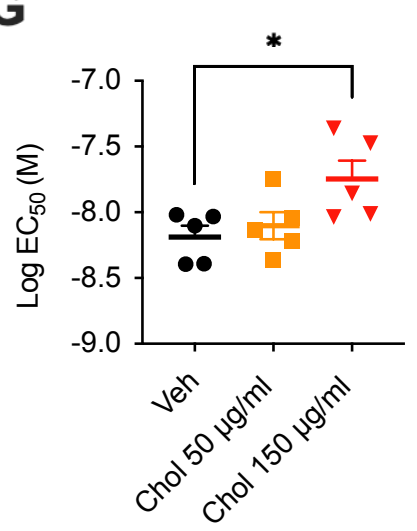

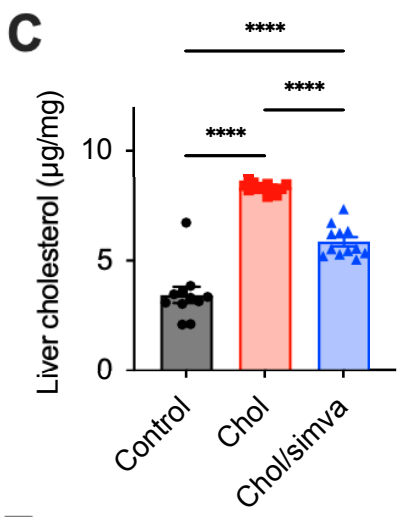

$\mathbf{E}$

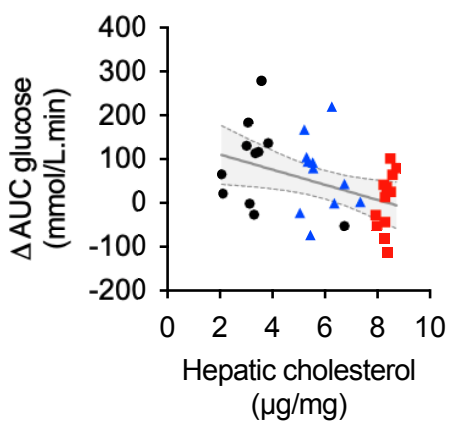

H

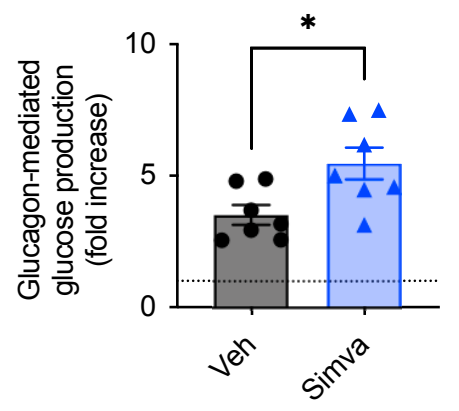

Figure 3: Increase in hepatic cholesterol in mice decreases responsiveness to glucagon. (A) body weight, (B) hepatic triglyceride, (C) hepatic cholesterol, (D) glucagon challenge test and (E) association between change in AUC during glucagon challenge test and hepatic cholesterol in mice fed different diets as indicated by colour code; the linear regression line $\pm 95 \%$ confidence intervals is shown; $n=12$ in each group. cAMP dose response curves $(\mathbf{F})$ and $\log \mathrm{EC}_{50}(\mathbf{G})$ in primary mouse hepatocytes pre-treated with cholesterol, then stimulated with glucagon; $n=5$, 4-parameter fit of pooled data shown; $(\mathbf{H})$ glucose production in primary mouse hepatocytes pretreated with simvastatin or vehicle overnight, then stimulated with glucagon for 24 hours, expressed as fold change over no-glucagon control stimulation, $n=7$. Data are represented as mean \pm SEM with individual replicates shown in some cases; statistical analysis performed with one-way ANOVA and Sidak's post-hoc test (A, B, C, G), two-way ANOVA and Sidak's post-hoc test (D), or unpaired t-test (H). 


\section{Discussion}

In this study we have demonstrated an inverse relationship between hepatocyte cholesterol and glucagon responsiveness, as measured in vitro by glucagon-stimulated cAMP and glucose production, and in vivo via the hyperglycaemic response to exogenous glucagon administration. Further, we have identified probable cholesterol binding sites on GCGR that could mediate these effects.

To our knowledge this is the first time the effect of cholesterol on GCGR function has been reported. Increasing membrane cholesterol enhances the function of some GPCRs, e.g. the $\alpha_{1 \mathrm{~A}}$-adrenergic receptor, and diminishes that of others, e.g. the cannabinoid receptor 1 (CB1) and $\beta_{1}$-adrenergic receptor (Abiko et al., 2021; Guixà-González et al., 2017). Interestingly, we previously showed that cholesterol depletion in pancreatic beta cells led to reductions in both CAMP signalling efficacy and ligand-induced endocytosis of the closely related GLP-1R (Buenaventura et al., 2019). This partly contrasts with our current GCGR results, in which cholesterol depletion reduced uptake of fluoresecent glucagon but increased cAMP signalling. The discrepancy may reflect inherent differences in the effect of cholesterol on the two receptors, though it is worth noting that GPCR function is also modulated by concomitantlyinteracting membrane proteins, e.g. RAMP2 for GCGR (McGlone et al., 2021), and other membrane constituents that differ depending on cell type, which could in turn impact the role played by cholesterol. Other class B GPCRs for which the impact of cholesterol manipulation have been studied are summarised in Supplementary Table 1, with GCGR being somewhat unique within this class in showing enhanced CAMP signalling after cholesterol depletion. 


\begin{tabular}{|c|c|c|}
\hline Class B GPCR & Cell model & Manipulation and effect \\
\hline $\begin{array}{l}\text { Calcitonin gene-related } \\
\text { peptide receptor } \\
\text { (CGRPR) }\end{array}$ & $\begin{array}{l}\text { Guinea pig gall bladder (Jennings et } \\
\text { al., 1999) smooth muscle }\end{array}$ & $\begin{array}{l}\text { Cholesterol-saturated M } \beta C D: \downarrow \text { CGRP- } \\
\text { induced action potentials }\end{array}$ \\
\hline \multirow[t]{2}{*}{$\begin{array}{l}\text { Glucagon-like peptide } \\
\text { receptor } 1 \text { (GLP-1R) }\end{array}$} & $\begin{array}{l}\text { INS-1 cells (Buenaventura et al., } \\
\text { 2019) }\end{array}$ & $\begin{array}{l}10 \mathrm{mM} M \beta C D: \downarrow \text { exendin-4-induced } \\
\text { cAMP efficacy and endocytosis }\end{array}$ \\
\hline & HEK293 cells (Lucey et al., 2021) & $\begin{array}{l}10 \mathrm{mM} M \beta C D: \downarrow \text { exendin-4-C16-induced } \\
\text { cAMP potency and endocytosis }\end{array}$ \\
\hline $\begin{array}{l}\text { Glucagon-like peptide } 2 \\
\text { receptor (GLP-2R) }\end{array}$ & $\begin{array}{l}\text { DLD-1 and BHK cells (Estall et al., } \\
\text { 2004) }\end{array}$ & $\begin{array}{l}10 \mathrm{mM} M \beta C D: \downarrow \text { GLP-2-induced } \\
\text { endocytosis, no effect on cAMP }\end{array}$ \\
\hline $\begin{array}{l}\text { Glucagon receptor } \\
\text { (GCGR) }\end{array}$ & $\begin{array}{l}\text { Huh7 cells and mouse hepatocytes } \\
\text { (this work) }\end{array}$ & $\begin{array}{l}1-10 \mathrm{mM} \mathrm{M \beta CD} \text {, statin treatment: } \uparrow \\
\text { glucagon-induced cAMP, } \downarrow \text { endocytosis; } \\
\text { opposite effect from cholesterol loading }\end{array}$ \\
\hline $\begin{array}{l}\text { Pituitary adenylate } \\
\text { cyclase-activating } \\
\text { polypeptide type } 1 \\
\text { receptor }\left(\mathrm{PAC}_{1} \mathrm{R}\right)\end{array}$ & PC12 (Emery et al., 2015) & $10 \mathrm{mM}$ MßCD: $\downarrow$ PACAP-38 cAMP efficacy \\
\hline $\begin{array}{l}\text { Parathyroid hormone } \\
\text { type } 1 \text { receptor (PTHR1) }\end{array}$ & $\begin{array}{l}\text { HEK293 cells (Tovey and Taylor, } \\
\text { 2013) }\end{array}$ & $\begin{array}{l}2 \% \mathrm{M} \beta C D: \text { no effect on PTH-induced } \\
\text { augmentation of carbochol-induced } \mathrm{Ca}^{2+} \\
\text { transients }\end{array}$ \\
\hline $\begin{array}{l}\text { Vasoactive intestinal } \\
\text { polypeptide receptor } 2 \\
\left(\mathrm{VPAC}_{2} \mathrm{R}\right)\end{array}$ & $\begin{array}{l}\text { Mouse gastric smooth muscle cells } \\
\text { (Mahavadi et al., 2013) }\end{array}$ & $10 \mathrm{mM} M \beta C D: \downarrow V I P$-induced endocytosis \\
\hline
\end{tabular}

Supplementary Table 1: Class B GPCRs for which the impact of membrane cholesterol modulation has been reported.

There are various mechanisms by which cholesterol and other lipids may alter the stability, ligand binding properties, and thus function of GPCRs (Reiter et al., 2017): direct competition with agonist binding at the orthosteric site; directly binding at an allosteric site to modulate receptor conformation and dynamics (Abiko et al., 2021); indirectly via a change in local membrane composition and properties; or a combination of the above (Guixà-González et al., 2017). Recent work has demonstrated that GCGR function can be affected by endogenous allosteric modulators (Han et al., 2015; McGlone et al., 2021). GCGR has computationally predicted potential allosteric cholesterol binding sites, but the validity of these so-called "CRAC" and "CARC" consensus motifs in general has been questioned (Taghon et al., 2021). 
Our recently developed MD simulation method to evaluate GPCR-lipid interactions (Song et al., 2021) has allowed us to identify probable binding sites for cholesterol on the GCGR, with residence times which differ slightly depending on the receptor state. Site-4, which has the longest cholesterol residence time and lowest $\mathrm{K}_{d}^{\text {app }}$, overlays with the observed binding of a negative allosteric regulator (Zhang et al., 2017) and antagonist (Jazayeri et al., 2016) in inactive GCGR structures. Cholesterol has been observed to bind to sites- $1 / 2 / 3$ in the structures of other G protein bound class B1 GPCRs, however site-4 is not observed in activelike conformations (Supplementary Table 2). Thus, we propose cholesterol binding to site-4 may be responsible for our observed decrease in glucagon responsiveness and mini- $\mathrm{G}_{\mathrm{s}}$ binding by shifting the population ensemble toward the inactive conformation, similar to that proposed for other GPCRs (Casiraghi et al., 2016). Additionally it is possible that lipid synergy may further regulate receptor signalling. For example sites-3/4 are in proximity to previously observed PIP 2 binding sites on GCGR (Ansell et al., 2020). Lipid interplay has been suggested to occur for anionic lipid binding to the ion channel Kir2.2 (Duncan et al., 2020a) and warrants further investigation in GPCRs.

\begin{tabular}{|l|l|l|}
\hline Class B GPCR & $\begin{array}{l}\text { Structures with modelled } \\
\text { cholesterol }\end{array}$ & $\begin{array}{l}\text { Structures with cholesterol bound at site- } \\
\mathbf{1 , - 2} \text { or -3 }\end{array}$ \\
\hline $\begin{array}{l}\text { Parathyroid hormone } \\
\text { type 1 receptor (PTHR1) }\end{array}$ & $\begin{array}{l}\text { 6NBF, 6NBI, 6NBH (Zhao et al., } \\
\text { 2019) }\end{array}$ & 6NBF (site-2), 6NBH (site-2, site-3) \\
\hline $\begin{array}{l}\text { Glucagon-like peptide } \\
\text { receptor 1 (GLP-1R) }\end{array}$ & 7DUQ, 7E14 (Cong et al., 2021) & 7DUQ (site-1, site-3), 7E14 (site-3) \\
\hline $\begin{array}{l}\text { Corticotrophin-releasing } \\
\text { factor 1 and 1 receptors } \\
\text { (CRF1R and CRF2R) }\end{array}$ & 6PB0, 6PB1 (Ma et al., 2020) & 6PB0 (site-2), 6PB1 (site-1, site-2) \\
\hline $\begin{array}{l}\text { Glucose-dependent } \\
\text { insulinotropic } \\
\text { polypeptide receptor } \\
\text { (GIPR) }\end{array}$ & 7DTY (Zhao et al., 2021) & 7DTY (site-2, site-3) \\
\hline $\begin{array}{l}\text { Growth hormone } \\
\text { releasing hormone } \\
\text { receptor (GHRHR) }\end{array}$ & 7CZ5 (Zhou et al., 2020) & N/A \\
\hline
\end{tabular}


Vasoactive intestinal polypeptide receptor 1 (VIP1R)

Supplementary Table 2: Class B GPCRs with deposited cholesterol binding sites on RCSB Protein Data Bank (https://www.rcsb.org; accessed $13^{\text {th }}$ October 2021)

An alternative mechanism for GCGR regulation may be receptor redistribution into distinct lipid nanodomains. Changes to the pool of accessible cholesterol within sphingomyelin enriched regions (Das et al., 2014), for example as a result of diet (Hermetet et al., 2019; Levental et al., 2016), may alter the combination of occupied cholesterol sites. Our observed mid-range $\mathrm{K}_{\mathrm{d}}^{\text {app }} \mathrm{s}$ are within the (patho)-physiological range of membrane cholesterol, rendering differential GCGR partitioning between lipid pools due to changes in cholesterol binding/unbinding a viable prospect.

Downstream of cAMP production, glucagon activates pathways that result in increased hepatic glucose production. Using dietary manipulation, we demonstrated that hepatic cholesterol content is inversely proportional to the hyperglycaemic response to a glucagon stimulus in mice. The effect observed was small, possibly due to compensatory mechanisms that make the investigation of glucagon sensitivity challenging in vivo (Janah et al., 2019). As glucagon exerts other effects on hepatic metabolism, including promoting amino acid and lipid catabolism, it would be valuable in the future to determine if these effects are similarly blunted. It is also unclear what the impact of cholesterol-mediated increases in GCGR internalisation could be, as suggested by our observations using fluorescent glucagon. GPCR internalisation is traditionally seen as a prequel to downregulation e.g. via lysosomal degradation, but sustained endosomal CAMP generation could alternatively lead to 
engagement with spatially constrained signalling networks not accessible to membraneresident receptor (Manchanda et al., 2021).

Our study has limitations. Firstly, each of the experimental approaches we used to manipulate cholesterol have their own individual caveats. $M \beta C D$ is likely to sequester additional lipids as well as cholesterol from the plasma membrane (Zidovetzki and Levitan, 2007), which could themselves influence receptor function (Ansell et al., 2020), although our study benefits from using lower $\mathrm{M} \beta C D$ concentrations than many others (see Supplementary Table 1). Inhibition of HMG-CoA reductase with statins reduces synthesis of not only cholesterol but also of intermediaries required for post-translational protein modifications including farnesylation and geranylgeranylation (Werner et al., 2002). The dietary changes we implemented in mice resulted in clear alterations to hepatic cholesterol content, but we cannot infer a plasma membrane-specific effect from this approach in isolation. Despite these caveats, we observed congruent results across different systems that support a role for cholesterol in the regulation of GCGR sensitivity. A second limitation of our study is that we are unable to state confidently whether manipulating the lipid environment of the GCGR influences its signalling properties primarily via a direct effect on receptor function, or by altering the spatial dynamics of GCGR relative to its intracellular effectors. These possibilities could be explored in follow up studies using, for example, membrane fractionation techniques, in vitro reconstituted systems, imaging approaches to co-visualise the receptor and its potential interactors, and solid-state NMR experiments at variable cholesterol concentrations.

There are several possible implications of our findings for human health and disease. Statin treatment is associated with an increased incidence of new-onset T2DM (Danaei et al., 2013; 
Wang et al., 2017) and progression of existing T2DM (Mansi et al., 2021), with the degree of low-density lipoprotein-cholesterol (LDL-C) reduction correlating with the likelihood of developing T2DM in these studies (Wang et al., 2017). Genetic polymorphisms of HMGCR and related genes that lead to reduced LDL-C also increase the probability of developing T2DM (Lotta et al., 2016; Swerdlow et al., 2015), whereas patients with monogenic familial hypercholesterolaemia have high levels of plasma and hepatic cholesterol but a reduced risk of incident T2DM (Besseling et al., 2015; Hoeg et al., 1984). Our data raise the intriguing possibility that these effects may occur in part via a reduction in hepatocyte membrane cholesterol increasing sensitivity to the hyperglycaemic effects of physiological glucagon.

Our data also potentially reconcile the observations that NAFLD is associated with both an increase in hepatic cholesterol (Min et al., 2012; Puri et al., 2007) and glucagon resistance (Albrechtsen et al., 2018; Gar et al., 2021). Contrasting with the possibility discussed above, i.e. that statin treatment might enhance glucagon sensitivity and thereby increase fasting blood glucose levels, glucagon resistance in NAFLD has paradoxically been proposed to drive impaired glucose tolerance and T2DM in a subset of patients. This may be via perturbation of the alpha cell-hepatocyte axis, whereby hepatocytes resistant to glucagon are less able to catabolise amino acids, with the resulting increases in plasma amino acid levels leading to hypersecretion of glucagon by alpha cells (Holst et al., 2017). In this context, hyperglucagonaemia is still capable of increasing glycaemia as glucagon resistance is incomplete. In view of these ostensibly opposite effects on glycaemia that could result from cholesterol-mediated glucagon resistance, further studies are needed to carefully examine which process dominates in different pathological states. Nevertheless, greater 
understanding of this relationship is likely to underpin new therapies for NAFLD (Younossi et al., 2021).

Antagonising glucagon signalling has long been proposed as a therapeutic strategy for T2DM (Cheng et al., 2020). Our data suggest that cholesterol binding site-4 could be targeted by small molecule allosteric modulators of GCGR activity, as has been achieved for other GPCRs (Lu et al., 2017). On the other hand, GCGR agonism is increasingly seen as a viable component of multi-incretin treatment for obesity and diabetes as, when combined with GLP-1R agonism, beneficial effects of glucagon (e.g. amelioration of hepatic steatosis and enhanced weight loss through increased energy expenditure) may be realised without unwanted hyperglycaemia (Ambery et al., 2018). Our work therefore suggests that it is worth evaluating whether lipidmodifying treatments can aid the effectiveness of therapeutic GCGR agonism in metabolic disease. 


\section{Acknowledgements}

ERM was supported by a UK Medical Research Council (MRC) Clinical Research Training Fellowship and an Early Career Grant from the Society of Endocrinology while working on this project. TBA is funded by the Wellcome Trust (102164/B/13/Z). AT and DC are funded by the MRC (MR/R010676/1 and MC-A654-5QB10, respectively). AT also acknowledges support from Diabetes UK and the European Federation for the Study of Diabetes. BJ is supported by the MRC (MR/R010676/1), IPPRF scheme, European Federation for the Study of Diabetes, Society for Endocrinology, British Society for Neuroendocrinology, and the UK National Institute for Health Research (NIHR) Imperial Biomedical Research Centre (BRC). TT is funded by the NIHR, the NIHR Imperial BRC and the J.P. Moulton Charitable Foundation. SRB is funded by the NIHR Imperial BRC. MS is supported by Wellcome Trust $(208361 / Z / 17 / Z$ and 220062/Z/20/Z) and the UK Biotechnology and Biological Sciences Research Council (BBSRC BB/R00126X/). The Department of Metabolism, Digestion and Reproduction at Imperial College London, UK, is funded by grants from the MRC, the BBSRC and is supported by the NIHR Imperial BRC. The views expressed are those of the authors and not necessarily those of the abovementioned funders, the UK National Health Service (NHS), the NIHR, or the UK Department of Health.

\section{Author contributions}

Conceptualization: ERM, BJ, TT, SRB; Methodology: BJ, AT, WS, TBA, MS; Investigation: ERM, $B J, C D, T B A$; Writing, reviewing and editing: all authors.

\section{Declaration of Interest}

The authors declare no competing interests 


\section{Materials and methods}

\section{Cell culture and primary mouse hepatocyte isolation}

Huh7-GCGR cells (McGlone et al., 2021) were cultured at $37^{\circ} \mathrm{C}$ in $5 \% \mathrm{CO}_{2}$ in DMEM supplemented with 10\% FBS, 1\% penicillin/streptomycin and 1\% G418 (Thermo Fisher). HEK293T cells were cultured similarly but without G418. Hepatocytes from male adult $\mathrm{C} 57 \mathrm{Bl} / 6 \mathrm{~J}$ mice were isolated using collagenase perfusion, as previously described (Woods et al., 2011). After washing and resuspension, primary hepatocytes were plated and cultured at $37^{\circ} \mathrm{C}$ in $5 \% \mathrm{CO}_{2}$ in Medium 199 supplemented with $1 \%$ penicillin/streptomycin, $1 \% \mathrm{BSA}, 2 \%$ Ultroser G, 100 nM T3, 100 nM dexamethasone and 100 nM insulin (all Thermo Fisher). After 5 hours, medium was changed to M199 with $1 \%$ penicillin/streptomycin, $100 \mathrm{nM}$ dexamethasone and $10 \mathrm{nM}$ insulin for serum starvation.

\section{Peptides}

Glucagon and a fluorescent glucagon analogue, "FITC-GCG", which conforms to the amino acid sequence of glucagon(1-29) with a C-terminal extension Gly30,31Lys32-FITC (fluorescein isothiocyanate) (McGlone et al., 2021), were obtained from Wuxi Apptec.

\section{Cholesterol-modulating treatments}

Cells in suspension or plated were treated with cholesterol-saturated methyl- $\beta$-cyclodextrin (referred to as "cholesterol" hereafter when in the context of cellular treatments; at $50 \mathrm{\mu g} / \mathrm{ml}$ unless otherwise stated), or cholesterol-depleted methyl- $\beta$-cyclodextrin ( $M \beta C D$; varying concentrations, Sigma Aldrich), in Hanks' buffered saline solution (HBSS), whilst being gently agitated or rocked for 30 minutes. Plated cells were treated with simvastatin $10 \mu \mathrm{M}$ and/or mevalonate $50 \mu \mathrm{M}$ (Sigma-Aldrich) for 16 hours in serum-free medium. All treatments were thoroughly washed off prior to experiments. 


\section{cAMP accumulation assay}

After cholesterol-modulating treatments as described above, Huh7-GCGR cells in 96-well plates were stimulated with indicated concentration of agonist in serum-free medium for 10 min at $37^{\circ} \mathrm{C}$. Where indicated, $10 \mu \mathrm{M}$ forskolin was used as a positive control, and results were normalised to the forskolin response. Where indicated, $10 \mathrm{ng} / \mathrm{ml}$ pertussis toxin (PTX; Sigma-Aldrich) was applied overnight in advance of the assay to inhibit $\mathrm{Ga}_{\mathrm{i}}$. Primary mouse hepatocytes in suspension were stimulated in serum-free DMEM with phosphodiesterase inhibitors (100 $\mu \mathrm{M}$ 3-isobutyl-1-methylxanthine; IBMX) for 10 minutes at $37^{\circ} \mathrm{C}$. After stimulation cells were lysed and cAMP was assayed by immunoassay (Cisbio HTRF cAMP Dynamic 2).

\section{Fluorescent glucagon uptake assay}

After cholesterol-modulating treatments as described above, Huh7-GCGR cells in 96-well black, clear bottom plates were stimulated with FITC-GCG for 10 minutes at $37^{\circ} \mathrm{C}$ in serumfree medium. Unbound agonist was removed by washing three times with HBSS, followed by fixation with 2\% paraformaldehyde (PFA) for 10 minutes at room temperature. High content imaging was performed using an automated Nikon Ti2 widefield microscope with a 0.75 numerical aperture $20 \times$ air objective, with 9 fields-of-view acquired per well, and internalised agonist was quantified from epifluorescence images as previously described (Pickford et al., 2021).

\section{Mini-Gs recruitment assay}

HEK293T cells were co-transfected using Lipofectamine 2000 with human GCGR bearing an N-terminal SNAP-tag and C-terminal SmBiT tag, plus LgBiT-tagged truncated $\mathrm{G}_{\mathrm{s}}$ subunit (mini-Gs-LgBiT, a gift from Prof Nevin Lambert, Medical College of Georgia), as previously 
described (Jones et al., 2020). At 36 hours, an equal number of detached cells were treated in suspension with cholesterol for $30 \mathrm{~min}$. After further washing, cells were resuspended in HBSS containing Furimazine (1:50 dilution; Promega) and dispensed into 96-well half-area white plates. After reading baseline luminescence over $8 \mathrm{~min}, 100 \mathrm{nM}$ glucagon or vehicle (HBSS) was added and signal serially recorded for $30 \mathrm{~min}$. Signal was normalised to the average baseline across all conditions within each experiment, and integrated area-undercurve was calculated.

\section{Molecular dynamics simulations and analysis}

Structures of the GCGR in inactive and active conformations were derived from the Protein Data Bank (PDB ID: inactive 5XEZ, active 6LMK) (Qiao et al., 2020; Zhang et al., 2017). Additional components (including bound glucagon in 6LMK) were removed and missing loops and/or incomplete residues were modelled using Modeller (Ansell et al., 2020; Fiser and Sali, 2003). The GCGR was coarse-grained using martinize.py (de Jong et al., 2013) and embedded in an asymmetric lipid bilayer membrane comprising POPC (20\%), DOPC (20\%), POPE (5\%), DOPE (5\%), sphingomyelin (15\%), GM3 (10\%) and cholesterol (25\%) in the upper leaflet and POPC (5\%), DOPC (5\%), POPE (20\%), DOPE (20\%), POPS (8\%), DOPS (7\%), PIP $2(10 \%)$ and cholesterol (25\%) in the lower leaflet using insane.py (Wassenaar et al., 2015). The MARTINI2.2 coarse grained (CG) forcefield (Marrink et al., 2007) was used to describe all components and cholesterol was modelled with the virtual site descriptor (Melo et al., 2015). The EINeDyn elastic network was applied to each protein with a cut-off of $0.9 \mathrm{~nm}$ and a spring force constant of $500 \mathrm{~kJ} \mathrm{~mol}^{-1} \mathrm{~nm}^{-2}$ (Periole et al., 2009). Each system was solvated using MARTINI water (Marrink et al., 2007) and $\sim 0.15 \mathrm{M} \mathrm{NaCl}$ before independent minimization and equilibration steps. Simulations were run identically to those described previously (Ansell et al., 2020) for $10 x 10 \mu$ s of each GCGR conformation. The GROMACS 5.14 and 2019 simulation 
packages were used to perform simulations (www.gromacs.org). Cholesterol interactions with GCGR were analysed using PyLipID (Song et al., 2021) with a 0.55/0.8 nm double cut-off to define lipid contact. Binding sites and kinetic analysis (i.e. derived residence times) were calculated by PyLipID as described in (Song et al., 2021).

\section{Computational binding saturation curves}

Binding saturation curves and site affinities were calculated in accordance with a recently published method (Ansell et al., 2021). GCGR (PDB ID: active 6LMK) was simulated in binary POPC:cholesterol bilayers of increasing cholesterol content $(1 \%, 2.5 \%, 5 \%, 10 \%, 15 \%, 30 \%$, 40\%). Each system was simulated for $5 \times 5 \mu$ s with CG simulation parameters as described above. The concentration of free cholesterol (\%) was defined as the mean number of unbound cholesterol (>0.8 $\mathrm{nm}$ from the GCGR transmembrane domain) divided by the total number of lipids in the bilayer. Site occupancies correspond to the mean occupancy of 6 residues at each site, as obtained by PyLipID. Apparent dissociation constants ( $\left.\mathrm{K}_{\mathrm{d}}{ }^{\mathrm{app}} \mathrm{s}\right)$ were calculated via fitting to equation 1 using Prism 9.2.0 for MacOS (Graphpad Software).

[1] Occupancy $=\frac{B_{\text {max }}^{a p p}+[C H O L]_{\text {free }}}{K_{d}^{a p p}+[C H O L]_{\text {free }}}$ Hepatocyte glucose output assay

Primary hepatocytes were serum-starved overnight with the addition of simvastatin $10 \mu \mathrm{M}$ or vehicle (DMSO). After a thorough wash to remove any phenol-red containing media, glucose production media was added to the wells (phenol-red free DMEM with $1 \mathrm{mM}$ sodium pyruvate (Gibco) and $20 \mathrm{mM}$ sodium lactate (Sigma). Baseline samples were taken before addition of glucagon $100 \mathrm{nM}$ or vehicle. The plate was incubated at $37^{\circ} \mathrm{C}$ for 24 hours, after which media was removed and stored at $-20^{\circ} \mathrm{C}$. Cellular protein was extracted and quantified using a BCA assay (Thermo Fisher). Glucose in media was assayed using a glucose oxidase 
assay (Randox), normalised to protein content of the well, and expressed as fold change of glucose production in the absence of glucagon.

\section{Animals and dietary manipulation}

Experiments were performed in accordance with the UK Animals (Scientific Procedures) Act 1986 and approved by the Animal Welfare and Ethical Review Board at Imperial College London. C57BL/6J male mice (Charles River) were group-housed in a pathogen-free facility at controlled temperature $\left(22^{\circ} \mathrm{C}\right)$ with a 12 -hour light dark cycle. Access to food was ad libitum, except prior to fasting studies, and mice always had free access to water. Mice were fed standard chow (SDS Rm3) during acclimatisation. Specialist chows were based on a standard Clinton/Cybulsky rodent diet ( $10 \% \mathrm{kcal}$ from fat and $70 \% \mathrm{kcal}$ from carbohydrate) and were identical in constitution and calorie content, with the exception of $0 \%$ or $0.5 \%$ added cholesterol, or $0.5 \%$ cholesterol and $120 \mathrm{mg}$ simvastatin per kg (Research Diets). Mice were fed specialist diets for at least 7 days before glucagon challenge test and 12 days before the cull.

\section{Glucagon challenge test}

Glucagon challenge tests was performed in the light phase, in mice fasted for 5 hours (Gelling et al., 2003; Rossi et al., 2018). Tail vein blood glucose was measured using a handheld glucometer (Nexus, GlucoRx) before and at intervals following intraperitoneal injection with sodium pyruvate $2 \mathrm{~g} / \mathrm{kg}$ (Sigma) as a gluconeogenic substrate \pm glucagon $10 \mathrm{nmol} / \mathrm{kg}$. Each mouse underwent the test with and without glucagon, in a random order, with an intervening washout period of 3 days. At the end of the study mice were culled using decapitation following a 5-hour fast. The liver was harvested, snap frozen in liquid nitrogen and stored at $-80^{\circ} \mathrm{C}$. 


\section{Lipid extraction}

Lipids were extracted from liver tissue by homogenization in ethanol $(0.03 \times \mathrm{w} / \mathrm{v})$ (Woods et al., 2017). Lipids were extracted from cells by agitation in butanol, before evaporation and resuspension in methanol.

\section{Cholesterol and triglyceride assays}

Triglyceride content of samples was measured using a GPO-PAP Triglyceride assay (Randox Laboratories Ltd) and cholesterol using Amplex Red Cholesterol Assay Kit (ThermoFisher Scientific).

\section{Statistical analyses}

All statistical analysis of experimental data was performed using Prism 9.0. Concentrationresponse curves were generated by 3-parameter logistic fitting or using a biphasic "bellshaped" fit. For CAMP, $E_{\max }$ and $\log _{10}$-transformed $\mathrm{EC}_{50}$ were derived for each repeat and then compared using t-tests or one-way ANOVA, with matched analyses performed where permitted by experimental design, and multiple comparison tests as indicated in the figure legends. For experiments using PTX, the $\mathrm{Ga}_{\mathrm{i}}$ component of the biphasic response was calculated by subtracting response in the presence of PTX (i.e. the $G \alpha_{s}$-specific response) from total response. For cellular treatments, as a combined measure of agonism, $E_{\max } / \mathrm{EC}_{50}$ was calculated and normalised to vehicle control; $\log _{10}$-transformed values were then used for simple linear regression analysis, with calculation of goodness of fit. $p<0.05$ was considered statistically significant. 


\section{References}

Abiko, L.A., Teixeira, R.D., Engilberge, S., Grahl, A., and Grzesiek, S. (2021). Filling of a waterfree void explains the allosteric regulation of the $\beta<$ sub $>1</$ sub $>$-adrenergic receptor by cholesterol. bioRxiv, 2021.2008.2030.457941. 10.1101/2021.08.30.457941.

Albrechtsen, N.J.W., Junker, A.E., Christensen, M., Hædersdal, S., Wibrand, F., Lund, A.M., Galsgaard, K.D., Holst, J.J., Knop, F.K., and Vilsbøll, T. (2018). Hyperglucagonemia correlates with plasma levels of non-branched-chain amino acids in patients with liver disease independent of type 2 diabetes. American Journal of Physiology-Gastrointestinal and Liver Physiology 314, G91-G96. 10.1152/ajpgi.00216.2017.

Ambery, P., Parker, V.E., Stumvoll, M., Posch, M.G., Heise, T., Plum-Moerschel, L., Tsai, L.-F., Robertson, D., Jain, M., Petrone, M., et al. (2018). MEDI0382, a GLP-1 and glucagon receptor dual agonist, in obese or overweight patients with type 2 diabetes: a randomised, controlled, double-blind, ascending dose and phase $2 a$ study. Lancet 391, 2607-2618. papers3://publication/doi/10.1016/S0140-6736(18)30726-8.

Ansell, T.B., Curran, L., Horrell, M.R., Pipatpolkai, T., Letham, S.C., Song, W., Siebold, C., Stansfeld, P.J., Sansom, M.S.P., and Corey, R.A. (2021). Relative Affinities of ProteinCholesterol Interactions from Equilibrium Molecular Dynamics Simulations. J Chem Theory Comput. 10.1021/acs.jctc.1c00547.

Ansell, T.B., Song, W., and Sansom, M.S.P. (2020). The Glycosphingolipid GM3 Modulates Conformational Dynamics of the Glucagon Receptor. Biophys J 119, 300-313. 10.1016/j.bpj.2020.06.009.

Besseling, J., Kastelein, J.J., Defesche, J.C., Hutten, B.A., and Hovingh, G.K. (2015). Association between familial hypercholesterolemia and prevalence of type 2 diabetes mellitus. JAMA 313, 1029-1036. 10.1001/jama.2015.1206.

Buenaventura, T., Bitsi, S., Laughlin, W.E., Burgoyne, T., Lyu, Z., Oqua, A.I., Norman, H., McGlone, E.R., Klymchenko, A.S., Correa, I.R., Jr., et al. (2019). Agonist-induced membrane nanodomain clustering drives GLP-1 receptor responses in pancreatic beta cells. PLoS Biol 17, e3000097. 10.1371/journal.pbio.3000097.

Casiraghi, M., Damian, M., Lescop, E., Point, E., Moncoq, K., Morellet, N., Levy, D., Marie, J., Guittet, E., Banères, J.-L., and Catoire, L.J. (2016). Functional Modulation of a G ProteinCoupled Receptor Conformational Landscape in a Lipid Bilayer. Journal of the American Chemical Society 138, 11170-11175. 10.1021/jacs.6b04432.

Cheng, C., Jabri, S., Taoka, B.M., and Sinz, C.J. (2020). Small molecule glucagon receptor antagonists: an updated patent review (2015-2019). Expert Opinion on Therapeutic Patents 30, 509-526. 10.1080/13543776.2020.1769600.

Cong, Z., Chen, L.-N., Ma, H., Zhou, Q., Zou, X., Ye, C., Dai, A., Liu, Q., Huang, W., Sun, X., et al. (2021). Molecular insights into ago-allosteric modulation of the human glucagon-like peptide1 receptor. Nat Commun 12, 3763. 10.1038/s41467-021-24058-z.

Danaei, G., Garcia Rodriguez, L.A., Fernandez Cantero, O., and Hernan, M.A. (2013). Statins and risk of diabetes: an analysis of electronic medical records to evaluate possible bias due to differential survival. Diabetes Care 36, 1236-1240. 10.2337/dc12-1756.

Das, A., Brown, M.S., Anderson, D.D., Goldstein, J.L., and Radhakrishnan, A. (2014). Three pools of plasma membrane cholesterol and their relation to cholesterol homeostasis. Elife 3 . 10.7554/eLife.02882. 
de Jong, D.H., Singh, G., Bennett, W.F., Arnarez, C., Wassenaar, T.A., Schafer, L.V., Periole, X., Tieleman, D.P., and Marrink, S.J. (2013). Improved Parameters for the Martini Coarse-Grained Protein Force Field. J Chem Theory Comput 9, 687-697. 10.1021/ct300646g.

Demant, M., Bagger, J.I., Suppli, M.P., Lund, A., Gyldenlove, M., Hansen, K.B., Hare, K.J., Christensen, M., Sonne, D.P., Holst, J.J., et al. (2018). Determinants of Fasting Hyperglucagonemia in Patients with Type 2 Diabetes and Nondiabetic Control Subjects. Metab Syndr Relat Disord 16, 530-536. 10.1089/met.2018.0066.

Duan, J., Shen, D.-d., Zhou, X.E., Bi, P., Liu, Q.-f., Tan, Y.-x., Zhuang, Y.-w., Zhang, H.-b., Xu, P.Y., Huang, S.-J., et al. (2020). Cryo-EM structure of an activated VIP1 receptor-G protein complex revealed by a NanoBiT tethering strategy. Nat Commun 11, 4121. 10.1038/s41467020-17933-8.

Duncan, A.L., Corey, R.A., and Sansom, M.S.P. (2020a). Defining how multiple lipid species interact with inward rectifier potassium (Kir2) channels. Proceedings of the National Academy of Sciences 117, 7803-7813. 10.1073/pnas.1918387117.

Duncan, A.L., Song, W., and Sansom, M.S.P. (2020b). Lipid-Dependent Regulation of Ion Channels and $G$ Protein-Coupled Receptors: Insights from Structures and Simulations. Annu Rev Pharmacol Toxicol 60, 31-50. 10.1146/annurev-pharmtox-010919-023411.

Emery, A.C., Liu, X.H., Xu, W., Eiden, M.V., and Eiden, L.E. (2015). Cyclic Adenosine 3',5'Monophosphate Elevation and Biological Signaling through a Secretin Family Gs-Coupled G Protein-Coupled Receptor Are Restricted to a Single Adenylate Cyclase Isoform. Mol Pharmacol 87, 928-935. 10.1124/mol.115.098087.

Estall, J.L., Yusta, B., and Drucker, D.J. (2004). Lipid raft-dependent glucagon-like peptide-2 receptor trafficking occurs independently of agonist-induced desensitization. Mol Biol Cell 15, 3673-3687. 10.1091/mbc.e03-11-0825.

Fiser, A., and Sali, A. (2003). Modeller: generation and refinement of homology-based protein structure models. Methods Enzymol 374, 461-491. 10.1016/S0076-6879(03)74020-8.

Gar, C., Haschka, S.J., Kern-Matschilles, S., Rauch, B., Sacco, V., Prehn, C., Adamski, J., Seissler, J., Wewer Albrechtsen, N.J., Holst, J.J., and Lechner, A. (2021). The liver-alpha cell axis associates with liver fat and insulin resistance: a validation study in women with non-steatotic liver fat levels. Diabetologia 64, 512-520. 10.1007/s00125-020-05334-x.

Gelling, R.W., Du, X.Q., Dichmann, D.S., Romer, J., Huang, H., Cui, L., Obici, S., Tang, B., Holst, J.J., Fledelius, C., et al. (2003). Lower blood glucose, hyperglucagonemia, and pancreatic alpha cell hyperplasia in glucagon receptor knockout mice. Proceedings of the National Academy of Sciences 100, 1438-1443. papers3://publication/doi/10.1073/pnas.0237106100.

Grady, T., Fickova, M., Tager, H.S., Trivedi, D., and Hruby, V.J. (1987). Stimulation and inhibition of cAMP accumulation by glucagon in canine hepatocytes. J Biol Chem 262, 1551415520.

Guixà-González, R., Albasanz, J.L., Rodriguez-Espigares, I., Pastor, M., Sanz, F., Martí-Solano, M., Manna, M., Martinez-Seara, H., Hildebrand, P.W., Martín, M., and Selent, J. (2017). Membrane cholesterol access into a G-protein-coupled receptor. Nat Commun 8, 14505. papers3://publication/doi/10.1038/ncomms14505.

Han, J., Zhang, M., Froese, S., Dai, F.F., Robitaille, M., Bhattacharjee, A., Huang, X., Jia, W., Angers, S., Wheeler, M.B., and Wei, L. (2015). The Identification of Novel Protein-Protein Interactions in Liver that Affect Glucagon Receptor Activity. PLoS ONE 10, e0129226. papers3://publication/doi/10.1371/journal.pone.0129226.

Hermetet, F., Buffiere, A., Aznague, A., Pais de Barros, J.P., Bastie, J.N., Delva, L., and Quere, R. (2019). High-fat diet disturbs lipid raft/TGF-beta signaling-mediated maintenance of 
hematopoietic stem cells in mouse bone marrow. Nat Commun 10, 523. 10.1038/s41467018-08228-0.

Hoeg, J.M., Demosky, S.J., Jr., Schaefer, E.J., Starzl, T.E., and Brewer, H.B., Jr. (1984). Characterization of hepatic low density lipoprotein binding and cholesterol metabolism in normal and homozygous familial hypercholesterolemic subjects. J Clin Invest 73, 429-436. 10.1172/JCI111229.

Holst, J.J., Wewer Albrechtsen, N.J., Pedersen, J., and Knop, F.K. (2017). Glucagon and Amino Acids Are Linked in a Mutual Feedback Cycle: The Liver- $\alpha$-Cell Axis. Diabetes 66, 235-240. papers3://publication/doi/10.2337/db16-0994.

Janah, L., Kjeldsen, S., Galsgaard, K.D., Winther-Sorensen, M., Stojanovska, E., Pedersen, J., Knop, F.K., Holst, J.J., and Wewer Albrechtsen, N.J. (2019). Glucagon Receptor Signaling and Glucagon Resistance. Int J Mol Sci 20. 10.3390/ijms20133314.

Jazayeri, A., Doré, A.S., Lamb, D., Krishnamurthy, H., Southall, S.M., Baig, A.H., Bortolato, A., Koglin, M., Robertson, N.J., Errey, J.C., et al. (2016). Extra-helical binding site of a glucagon receptor antagonist. Nature 533, 274-277. papers3://publication/doi/10.1038/nature17414. Jennings, L.J., Xu, Q.W., Firth, T.A., Nelson, M.T., and Mawe, G.M. (1999). Cholesterol inhibits spontaneous action potentials and calcium currents in guinea pig gallbladder smooth muscle. Am J Physiol 277, G1017-1026. 10.1152/ajpgi.1999.277.5.G1017.

Jones, B., McGlone, E.R., Fang, Z., Pickford, P., Correa, I.R., Jr., Oishi, A., Jockers, R., Inoue, A., Kumar, S., Gorlitz, F., et al. (2020). Genetic and biased agonist-mediated reductions in betaarrestin recruitment prolong cAMP signalling at glucagon family receptors. J Biol Chem. 10.1074/jbc.RA120.016334.

Levental, K.R., Lorent, J.H., Lin, X., Skinkle, A.D., Surma, M.A., Stockenbojer, E.A., Gorfe, A.A., and Levental, I. (2016). Polyunsaturated Lipids Regulate Membrane Domain Stability by Tuning Membrane Order. Biophys J 110, 1800-1810. 10.1016/j.bpj.2016.03.012.

Liang, Y.-L., Khoshouei, M., Radjainia, M., Zhang, Y., Glukhova, A., Tarrasch, J., Thal, D.M., Furness, S.G.B., Christopoulos, G., Coudrat, T., et al. (2017). Phase-plate cryo-EM structure of a class B GPCR-G-protein complex. Nature 546, 118-123. 10.1038/nature22327.

Longuet, C., Sinclair, E.M., Maida, A., Baggio, L.L., Maziarz, M., Charron, M.J., and Drucker, D.J. (2008). The glucagon receptor is required for the adaptive metabolic response to fasting. Cell Metab. 8, 359-371. papers3://publication/doi/10.1016/j.cmet.2008.09.008.

Lotta, L.A., Sharp, S.J., Burgess, S., Perry, J.R.B., Stewart, I.D., Willems, S.M., Luan, J., Ardanaz, E., Arriola, L., Balkau, B., et al. (2016). Association Between Low-Density Lipoprotein Cholesterol-Lowering Genetic Variants and Risk of Type 2 Diabetes: A Meta-analysis. JAMA 316, 1383-1391. 10.1001/jama.2016.14568.

Lu, J., Byrne, N., Wang, J., Bricogne, G., Brown, F.K., Chobanian, H.R., Colletti, S.L., Di Salvo, J., Thomas-Fowlkes, B., Guo, Y., et al. (2017). Structural basis for the cooperative allosteric activation of the free fatty acid receptor GPR40. Nat. Struct. Mol. Biol. 24, 570-577. 10.1038/nsmb.3417.

Lucey, M., Ashik, T., Marzook, A., Wang, Y., Goulding, J., Oishi, A., Broichhagen, J., Hodson, D.J., Minnion, J., Elani, Y., et al. (2021). <strong>Acylation of the incretin peptide exendin-4 directly impacts GLP-1 receptor signalling and trafficking $</$ strong $>$. Mol. Pharmacol., MOLPHARM-AR-2021-000270. 10.1124/molpharm.121.000270.

Ma, S., Shen, Q., Zhao, L.-H., Mao, C., Zhou, X.E., Shen, D.-D., de Waal, P.W., Bi, P., Li, C., Jiang, $Y$., et al. (2020). Molecular Basis for Hormone Recognition and Activation of CorticotropinReleasing Factor Receptors. Mol. Cell 77, 669-680.e664. https://doi.org/10.1016/i.molcel.2020.01.013. 
Mahavadi, S., Bhattacharya, S., Kim, J., Fayed, S., Al-Shboul, O., Grider, J.R., and Murthy, K.S. (2013). Caveolae-dependent internalization and homologous desensitization of VIP/PACAP receptor, $\mathrm{VPAC}_{2}$, in gastrointestinal smooth muscle. Peptides 43, 137-145. 10.1016/j.peptides.2013.03.008.

Mahmood, I., Liu, X., Neya, S., and Hoshino, T. (2013). Influence of lipid composition on the structural stability of g-protein coupled receptor. Chem Pharm Bull (Tokyo) 61, 426-437. 10.1248/cpb.c12-01059.

Manchanda, Y., Bitsi, S., Kang, Y., Jones, B., and Tomas, A. (2021). Spatiotemporal control of GLP-1 receptor activity. Current Opinion in Endocrine and Metabolic Research 16, 19-27. papers3://publication/uuid/BDD2AF9C-77FE-47EA-9F30-8D4584531A94.

Manna, M., Niemela, M., Tynkkynen, J., Javanainen, M., Kulig, W., Muller, D.J., Rog, T., and Vattulainen, I. (2016). Mechanism of allosteric regulation of beta2-adrenergic receptor by cholesterol. Elife 5. 10.7554/eLife.18432.

Mansi, I.A., Chansard, M., Lingvay, I., Zhang, S., Halm, E.A., and Alvarez, C.A. (2021). Association of Statin Therapy Initiation With Diabetes Progression: A Retrospective MatchedCohort Study. JAMA Intern Med. 10.1001/jamainternmed.2021.5714.

Marrink, S.J., Risselada, H.J., Yefimov, S., Tieleman, D.P., and de Vries, A.H. (2007). The MARTINI force field: coarse grained model for biomolecular simulations. J Phys Chem B 111, 7812-7824. 10.1021/jp071097f.

McGlone, E.R., Manchanda, Y., Jones, B., Pickford, P., Inoue, A., Carling, D., Bloom, S.R., Tan, T., and Tomas, A. (2021). Receptor Activity-Modifying Protein 2 (RAMP2) alters glucagon receptor trafficking in hepatocytes with functional effects on receptor signalling. Mol Metab 53, 101296. 10.1016/j.molmet.2021.101296.

Melo, M.N., Ingolfsson, H.I., and Marrink, S.J. (2015). Parameters for Martini sterols and hopanoids based on a virtual-site description. J Chem Phys 143, 243152. 10.1063/1.4937783. Min, H.K., Kapoor, A., Fuchs, M., Mirshahi, F., Zhou, H., Maher, J., Kellum, J., Warnick, R., Contos, M.J., and Sanyal, A.J. (2012). Increased hepatic synthesis and dysregulation of cholesterol metabolism is associated with the severity of nonalcoholic fatty liver disease. Cell Metab 15, 665-674. 10.1016/j.cmet.2012.04.004.

Nehme, R., Carpenter, B., Singhal, A., Strege, A., Edwards, P.C., White, C.F., Du, H., Grisshammer, R., and Tate, C.G. (2017). Mini-G proteins: Novel tools for studying GPCRs in their active conformation. PLOS ONE 12, e0175642. 10.1371/journal.pone.0175642.

Penhos, J.C., Wu, C.H., Daunas, J., Reitman, M., and Levine, R. (1966). Effect of glucagon on the metabolism of lipids and on urea formation by the perfused rat liver. Diabetes $15,740-$ 748.

Periole, X., Cavalli, M., Marrink, S.J., and Ceruso, M.A. (2009). Combining an Elastic Network With a Coarse-Grained Molecular Force Field: Structure, Dynamics, and Intermolecular Recognition. J Chem Theory Comput 5, 2531-2543. 10.1021/ct9002114.

Pickford, P., Lucey, M., Rujan, R.M., McGlone, E.R., Bitsi, S., Ashford, F.B., Corrêa, I.R., Hodson, D.J., Tomas, A., Deganutti, G., et al. (2021). Partial agonism improves the anti-hyperglycaemic efficacy of an oxyntomodulin-derived GLP-1R/GCGR co-agonist. Mol Metab 51, 101242. 10.1016/j.molmet.2021.101242.

Puri, P., Baillie, R.A., Wiest, M.M., Mirshahi, F., Choudhury, J., Cheung, O., Sargeant, C., Contos, M.J., and Sanyal, A.J. (2007). A lipidomic analysis of nonalcoholic fatty liver disease. Hepatology 46, 1081-1090. 10.1002/hep.21763. 
Qiao, A., Han, S., Li, X., Li, Z., Zhao, P., Dai, A., Chang, R., Tai, L., Tan, Q., Chu, X., et al. (2020). Structural basis of $G s$ and Gi recognition by the human glucagon receptor. Science 367, 13461352. 10.1126/science.aaz5346.

Reiter, E., Ayoub, M.A., Pellissier, L.P., Landomiel, F., Musnier, A., Tréfier, A., Gandia, J., De Pascali, F., Tahir, S., Yvinec, R., et al. (2017). $\beta$-arrestin signalling and bias in hormoneresponsive GPCRs. Mol Cell Endocrinol 449, 28-41. 10.1016/j.mce.2017.01.052.

Rossi, M., Zhu, L., McMillin, S.M., Pydi, S.P., Jain, S., Wang, L., Cui, Y., Lee, R.J., Cohen, A.H., Kaneto, H., et al. (2018). Hepatic Gi signaling regulates whole-body glucose homeostasis. J. Clin. Invest. 128, 746-759. papers3://publication/doi/10.1172/JCl94505.

Simons, K., and Ikonen, E. (2000). How cells handle cholesterol. Science 290, 1721-1726. 10.1126/science.290.5497.1721.

Song, W., Corey, R.A., Ansell, T.B., Cassidy, C.K., Horrell, M.R., Duncan, A.L., Stansfeld, P.J., and Sansom, M.S.P. (2021). PyLipID: A Python package for analysis of protein-lipid interactions from MD simulations. bioRxiv, 2021.2007.2014.452312. 10.1101/2021.07.14.452312.

Suppli, M.P., Bagger, J.I., Lund, A., Demant, M., van Hall, G., Strandberg, C., Konig, M.J., Rigbolt, K., Langhoff, J.L., Wewer Albrechtsen, N.J., et al. (2020). Glucagon Resistance at the Level of Amino Acid Turnover in Obese Subjects With Hepatic Steatosis. Diabetes 69, 10901099. 10.2337/db19-0715.

Swerdlow, D.I., Preiss, D., Kuchenbaecker, K.B., Holmes, M.V., Engmann, J.E., Shah, T., Sofat, R., Stender, S., Johnson, P.C., Scott, R.A., et al. (2015). HMG-coenzyme A reductase inhibition, type 2 diabetes, and bodyweight: evidence from genetic analysis and randomised trials. Lancet 385, 351-361. 10.1016/S0140-6736(14)61183-1.

Taghon, G.J., Rowe, J.B., Kapolka, N.J., and Isom, D.G. (2021). Predictable cholesterol binding sites in GPCRs lack consensus motifs. Structure 29, 499-506.e493. https://doi.org/10.1016/j.str.2021.01.004.

Thal, D.M., Glukhova, A., Sexton, P.M., and Christopoulos, A. (2018). Structural insights into G-protein-coupled receptor allostery. Nature 559, 45-53. 10.1038/s41586-018-0259-z.

Tovey, S.C., and Taylor, C.W. (2013). Cyclic AMP directs inositol (1,4,5)-trisphosphate-evoked Ca2+ signalling to different intracellular Ca2+ stores. J Cell Sci 126, 2305-2313. $10.1242 /$ jcs.126144.

Wang, S., Cai, R., Yuan, Y., Varghese, Z., Moorhead, J., and Ruan, X.Z. (2017). Association between reductions in low-density lipoprotein cholesterol with statin therapy and the risk of new-onset diabetes: a meta-analysis. Sci Rep 7, 39982. 10.1038/srep39982.

Wassenaar, T.A., Ingolfsson, H.I., Bockmann, R.A., Tieleman, D.P., and Marrink, S.J. (2015). Computational Lipidomics with insane: A Versatile Tool for Generating Custom Membranes for Molecular Simulations. J Chem Theory Comput 11, 2144-2155. 10.1021/acs.jctc.5b00209. Werner, N., Nickenig, G., and Laufs, U. (2002). Pleiotropic effects of HMG-CoA reductase inhibitors. Basic Res Cardiol 97, 105-116. 10.1007/s003950200000.

Woods, A., Heslegrave, A.J., Muckett, P.J., Levene, A.P., Clements, M., Mobberley, M., Ryder, T.A., Abu-Hayyeh, S., Williamson, C., Goldin, R.D., et al. (2011). LKB1 is required for hepatic bile acid transport and canalicular membrane integrity in mice. Biochem J 434, 49-60. 10.1042/BJ20101721.

Woods, A., Williams, J.R., Muckett, P.J., Mayer, F.V., Liljevald, M., Bohlooly, Y.M., and Carling, D. (2017). Liver-Specific Activation of AMPK Prevents Steatosis on a High-Fructose Diet. Cell Rep 18, 3043-3051. 10.1016/j.celrep.2017.03.011. 
Yajima, M., Hosoda, K., Kanbayashi, Y., Nakamura, T., Nogimori, K., Mizushima, Y., Nakase, Y., and Ui, M. (1978). Islets-activating protein (IAP) in Bordetella pertussis that potentiates insulin secretory responses of rats. Purification and characterization. J Biochem 83, 295-303. 10.1093/oxfordjournals.jbchem.a131904.

Younossi, Z.M., Stepanova, M., Ong, J., Trimble, G., AlQahtani, S., Younossi, I., Ahmed, A., Racila, A., and Henry, L. (2021). Nonalcoholic Steatohepatitis Is the Most Rapidly Increasing Indication for Liver Transplantation in the United States. Clin Gastroenterol Hepatol 19, 580589 e585. 10.1016/j.cgh.2020.05.064.

Zhang, H., Qiao, A., Yang, D., Yang, L., Dai, A., de Graaf, C., Reedtz-Runge, S., Dharmarajan, V., Zhang, H., Han, G.W., et al. (2017). Structure of the full-length glucagon class B G-proteincoupled receptor. Nature 7, 339. papers3://publication/doi/10.1038/nature22363.

Zhao, F., Zhang, C., Zhou, Q., Hang, K., Zou, X., Chen, Y., Wu, F., Rao, Q., Dai, A., Yin, W., et al. (2021). Structural insights into hormone recognition by the human glucose-dependent insulinotropic polypeptide receptor. Elife 10. 10.7554/eLife.68719.

Zhao, L.H., Ma, S., Sutkeviciute, I., Shen, D.D., Zhou, X.E., de Waal, P.W., Li, C.Y., Kang, Y., Clark, L.J., Jean-Alphonse, F.G., et al. (2019). Structure and dynamics of the active human parathyroid hormone receptor-1. Science 364, 148-153. 10.1126/science.aav7942.

Zhou, F., Zhang, H., Cong, Z., Zhao, L.-H., Zhou, Q., Mao, C., Cheng, X., Shen, D.-D., Cai, X., Ma, C., et al. (2020). Structural basis for activation of the growth hormone-releasing hormone receptor. Nat Commun 11, 5205. 10.1038/s41467-020-18945-0.

Zidovetzki, R., and Levitan, I. (2007). Use of cyclodextrins to manipulate plasma membrane cholesterol content: evidence, misconceptions and control strategies. Biochim Biophys Acta 1768, 1311-1324. 10.1016/j.bbamem.2007.03.026. 